\title{
REPRESENTAÇÕES DE DOCENTES SOBRE ALUNOS(AS) DAS CLASSES POPULARES
}

\section{TEACHERS' REPRESENTATIONS ON STUDENTS OF POPULAR CLASSES}

\author{
REPRESENTACIONES DE PROFESORES SOBRE ESTUDIANTES \\ DE CLASES POPULARES
}

Andrea Porto Ribeiro ${ }^{1}$; Vanesssa Therezinha Bueno Campos $^{2}$

\section{RESUMO}

Nesse artigo apresentamos reflexões oriundas de uma pesquisa desenvolvida entre os anos de 2015 a 2017 , na Linha de Pesquisa Saberes e Práticas Educativas, no âmbito do Programa de Pós-Graduação em Educação, curso de Mestrado, da Universidade Federal de Uberlândia, cujos objetivos encontram-se vinculados à luta pela Educação Pública com qualidade e socialmente referenciada, a favor das classes populares. Com base nos escritos de Freire $(1987,1996)$, de Brandão (1983), de Novais (2002), de Streck $(2008,2009)$ relativos a escolarização das classes populares no Brasil; de Sacristán (2005) sobre construção social do aluno(a); de Oliveira (2002); de Kuhlmann (2015) dentre outros, a respeito de educação e infância, e nas proposições de Moscovici $(1961,2007)$ e de Alves-Mazzotti $(2008,2010)$ sobre a Teoria das Representações Sociais, analisamos as representações dos(as) professores(as) da Educação Infantil sobre estudantes das classes populares de escolas da rede municipal de Uberlândia - MG, destacando elementos que exemplificam seus sentidos e significados. Optamos dessa forma, por compreender os sistemas de referência mediante a relação entre o campo teórico metodológico das Representações Sociais articulados ao legado da Educação Popular. Esperamos, por conseguinte, contribuir para esclarecer aspectos sobre as oportunidades de escolarização das classes populares, especialmente aquelas relativas às representações de docentes sobre alunos(as) e a possibilidade de efetivação do acesso e permanência a Educação formal como direito humano.

PALAVRAS-CHAVE: Classes populares. Infância. Representações sociais.

\footnotetext{
${ }^{1}$ Doutoranda em Educação - Universidade Federal de Uberlândia (UFU). Uberlândia, MG - Brasil. Professora da educação básica - Escola de Aplicação - Universidade Federal de Uberlândia (ESEBA/UFU). Uberlândia, MG Brasil. E-mail: andreaportoribeiro@gmail.com

${ }^{2}$ Doutora e Pós-doutora em Educação - Universidade de São Paulo (USP). São Paulo, SP - Brasil. Professora nos cursos de licenciaturas e no Programa de Pós-Graduação - Faculdade de Educação - Universidade de Uberlândia (UFU). Uberlândia, MG - Brasil. E-mail: vbcampos@terra.com.br

Submetido em: 21/03/2020 - Aceito em: 06/01/2021
}

(C) ETD-Educação Temática Digital Campinas, SP $\quad$ v.23 $\quad$ n.4 $\quad$ p.982-1001 out./dez. 2021




\section{ABSTRACT}

In this article we present reflections from research developed between the years 2015 to 2017, in the Research Line of Knowledge and Educational Practices, within the scope of the Postgraduate Program in Education, Master's course, from the Federal University of Uberlandia, whose objectives meet to be linked to the fight for Public Education with quality and socially referenced, in favor of the popular classes. Based on the writings of Freire (1987, 1996), Brandão (1983), Novais (2002), Streck $(2008,2009)$ regarding schooling of popular classes in Brazil, Sacristán (2005) on the social construction of the student, Oliveira (2002), Kuhlmann (2015) among others about education and childhood, and in the propositions of Moscovici $(1961,2007)$ and Alves-Mazzotti $(2008,2010)$ on the Theory of Social Representations, we analyze the teachers' representations of Early Childhood Education on students of popular classes of municipal schools of Uberlandia - MG, highlight elements that exemplify its meaning. In this way, we chose to understand the reference systems through the relationship between the theoretical methodological field of Social Representations linked to the legacy of Popular Education. We hope, therefore, to contribute to clarify aspects about the schooling opportunities of the popular classes, especially those related to teachers' representations about students and the possibility of effecting access and permanence to formal Education as a human right.

KEYWORDS: Popular classes. Childhood. Social representations.

\section{RESUMEN}

En este artículo presentamos reflexiones de una investigación desarrollada entre los años 2015 a 2017, en la Línea de Investigación de Conocimiento y Prácticas Educativas, dentro del alcance del Programa de Posgrado en Educación, Máster, de la Universidad Federal de Uberlândia, cuyos objetivos cumplen estar vinculado a la lucha por la Educación Pública con calidad y referencia social, a favor de las clases populares. Con base en los escritos de Freire (1987, 1996), Brandão (1983), Novais (2002), Streck (2008, 2009) sobre la escolarización de clases populares en Brasil, Sacristán (2005) sobre la construcción social del estudiante ( a), Oliveira (2002), Kuhlmann (2015) entre otros sobre educación y niñez, y en las proposiciones de Moscovici $(1961,2007)$ y Alves-Mazzotti $(2008,2010)$ sobre la Teoría de las representaciones sociales, analizamos las representaciones de professores sobre estudiantes de clases populares de Educación de la Primera Infancia sobre estidiantes de las clases populares de escuelas em la red municipal de Uberlândia - MG, ressaltando elementos que ejemplifican los sentidos y los significados. De esta forma, elegimos entender los sistemas de referencia a través de la relación entre el campo metodológico teórico de las Representaciones Sociales vinculadas al legado de la Educación Popular. Esperamos contribuir a aclarar aspectos sobre las oportunidades de escolarización de las clases populares, especialmente las relacionadas con las representaciones de los docentes sobre los estudiantes y la posibilidad de efectuar el acceso y la permanencia a la Educación formal como un derecho humano.

PALABRAS-CLAVE: Clases populares. Infancia. Representaciones sociales.

\section{INTRODUÇÃO}

Apresentamos neste texto reflexões oriundas de uma pesquisa desenvolvida entre os anos de 2015 a 2017, na Linha de Pesquisa Saberes e Práticas Educativas, no âmbito do Programa de Pós-Graduação em Educação, curso de Mestrado, da Universidade Federal de Uberlândia, cujos objetivos encontram-se vinculados à luta pela Educação Pública com qualidade e socialmente referenciada, a favor das classes populares.

Destacamos essa opção como militância teórico-prática alinhada ao pensamento de Freire (1996) que concebe a Educação como fenômeno social, político impregnado de intencionalidade e que deve ser realizado para humanização de todos(as). Significa, consequentemente, a tomada de decisão frente a trajetória escolar subalternizada a qual

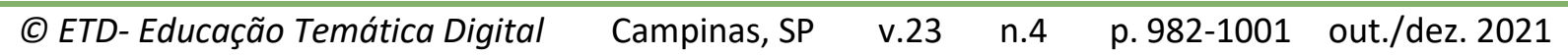


sujeitos populares foram submetidos. Configura-se como luta permanente em prol de processos educativos transformadores que contribuam para conscientização, empoderamento e democratização da produção e comunicação do conhecimento. Desse modo, a educação é, simultaneamente, "um ato político e um ato estético" (FREIRE; SHOR, 1986, p. 146).

A garantia de uma educação democrática, pública e popular para todos e todas, exige mudanças de paradigmas dos sujeitos que compõem a escola, bem como das Políticas Públicas Educacionais, ou seja, requer alterações na organização do sistema de ensino em suas diversas dimensões, sejam elas de infraestrutura, de valorização do trabalho docente, de formação inicial e permanente dos profissionais da Educação. Nesse viés, percebemos que a alteração mais difícil refere-se à transformação do conjunto de crenças e valores que nos constituem como seres humanos socioculturais, uma vez que estes elementos têm raízes profundas que ancoram o pensamento e as práticas individuais e coletivas. A possibilidade de alteração dos elementos simbólicos que organizam as estruturas sociais poderá provocar modificações nas diferentes esferas que constituem a Educação e no processo educativo e, por esse ponto de vista, é necessário desvelar quais são as forças de manutenção do status quo que estão em disputa e/ou negociação no campo socioeducativo.

Com base nos escritos de Freire $(1987,1996)$, de Brandão (1983), de Novais (2002), de Streck $(2008,2009)$ sobre a escolarização das classes populares no Brasil; de Sacristán (2005) sobre a construção social do(a) aluno(a), de Moscovici (1961, 2007) e Alves-Mazzotti (2008, 2010) sobre a Teoria das Representações Sociais (TRS), a pesquisa realizada buscou apreender os sentidos e significados das representações dos(as) professores(as) da Educação Infantil, de escolas da rede municipal de Uberlândia - MG, sobre estudantes das classes populares, a fim de discutirmos o impacto dos sistemas de referência na qualidade social da educação.

Esperamos, dessa forma, contribuir para esclarecer, pautadas reflexões apresentadas, aspectos relativos às oportunidades de escolarização das classes populares, especialmente àquelas relativas a discussão das representações de professores sobre as crianças matriculadas na pré-escola e a possibilidade de efetivação do direito a Educação formal como direito humano, com vistas a produção de conhecimentos que envolvam estudos sobre os saberes, as práticas educativas, representações sociais e Educação Popular. Objetivamos também, com base nos achados da pesquisa, contribuir para ampliar o debate sobre as políticas públicas destinadas à formação contínua de professores(as) fundamentado na reflexão sobre as necessidades formativas no contexto da escola pública. 


\title{
2 REFLEXÕES PRELIMINARES: A EDUCAÇÃO POPULAR E AS CRIANÇAS DAS CLASSES POPULARES
}

Empreender ações em defesa da escolarização das classes populares significa também a adesão a Educação Popular (EP). No Brasil, tal como nos demais países latino-americanos, a trajetória da EP construiu-se de forma multifacetada, ligada principalmente aos movimentos sociais. De acordo com Brandão e Assumpção (2009, p. 9), a EP é uma "cultura rebelde que transcende o tempo e o espaço", que luta pela apropriação do conhecimento pelas classes populares, envolve tomada de consciência e "[...] traduz a passagem de sujeitos e classes econômicas, para sujeitos e classes políticos" (BRANDÃO, 1983, p. 92). Em suas reflexões Brandão, (1983, p. 51-52) acrescenta:

\begin{abstract}
A educação popular é, hoje, a possibilidade da prática regida pela diferença, desde que a sua razão tenha uma mesma direção: o fortalecimento do poder popular, através da construção de um saber de classe. Portanto, mais importante do que pretender defini-la, fixar a verdade de seu ser, é descobrir onde ele se realiza e apontar as tendências através das quais ela transforma a educação na vivência da educação popular. Como outras tantas - os médicos militantes falam em medicina comunitária e os setores avançados da Igreja falam em pastoral popular - a educação popular é uma prática social. Melhor, é um domínio de convergência de práticas sociais que têm a ver, especificamente, com a questão do conhecimento. Com a questão da possibilidade da construção de um saber popular. Da apropriação, pelas classes populares, do seu próprio saber. Aquilo que é a fala e a lógica que traduzem a passagem de sujeitos e classes econômicos, para sujeitos e classes políticos.
\end{abstract}

Cabe ressaltar que a Educação Popular está intimamente vinculada com a obra do educador Paulo Freire, como enfatiza Maciel (2011, p. 329):

[...] falar em Educação Popular é falar impreterivelmente do legado do Educador Paulo Freire (1921-1997) que trouxe importantes reflexões sobre os sujeitos postos à margem da sociedade do capital. Por entender as classes populares como detentoras de um saber não valorizado e excluídas do conhecimento historicamente acumulado pela sociedade, nos mostra a relevância de se construir uma Educação a partir do conhecimento do povo e com o povo provocando uma leitura da realidade na ótica do oprimido, que ultrapasse as fronteiras das letras e se constitui nas relações históricas e sociais. Nesse sentido, o oprimido deve sair desta condição de opressão a partir da fomentação da consciência de classe oprimida.

A vocação ontológica do homem é "ser mais", declara Freire (1987), todavia a educação escolar ofertada às pessoas das classes populares, frequentemente, caminha em direção oposta. Nessa perspectiva, Novais (2002, p. 17), ao discutir sobre Educação Popular e Educação conservadora, considera que: 
[...] a Educação tradicional elimina a possibilidade do gesto educativo ser um gesto criador e comunicador das várias histórias (...), dificultando a construção e a valorização das identidades socioculturais. Além disso, parcelas significativas das instituições de ensino público - via de acesso das camadas populares ao ensino formal - mantêm práticas pedagógicas fundadas numa concepção de conhecimento a-histórico, pronto e neutro.

Nesse processo de exclusão nas escolas, a compreensão de professores(as) sobre seus alunos e alunas interfere no processo educacional, nas formas de as perceber, sentir e, consequentemente, no modo como desenvolvem suas práticas educativas. As representações docentes sobre a infância são constructos históricos e a identidade social atribuída por eles às crianças, na Educação Infantil, anuncia sentidos e significados oriundos de diversos contextos, tempo e espaço. De modo similar, o "significado atribuído à criança pauta-se em imagens sociais construídas ao longo do processo histórico e que funcionam como reguladores de processos educacionais dirigidos ao infante" (ANDRADE; SANTOS, 2009, p. 107).

Partindo do pressuposto de que, historicamente as culturas infantis se realizam em um contexto social específico, correspondente as condições em que as crianças vivem, a apropriação e reprodução interativa da cultura estará condicionada a organização do tempo e espaço que as crianças ocupam, bem como a condição social, étnica e de gênero que atravessa e marca esses sujeitos. Existem crianças e infâncias distintas e a esse respeito, Cunha e Santos (2014, p. 357) ponderam que:

[...] em razão das circunstâncias sociais, econômicas e políticas vividas pelas crianças, cada qual tem uma infância diferente, como podemos perceber nas distintas realidades vividas por crianças que têm acesso às tecnologias, brinquedos industrializados, passeios em shoppings, cinemas, enquanto outras, que vivem nas zonas rurais ou nas periferias, apresentam uma cultura diferente, com brinquedos construídos por eles mesmo, brincadeiras livres e pouco acesso às tecnologias. Assim, as brincadeiras e modo pelo qual as crianças vivem suas infâncias são distintos e marcados pela organização social e pela cultura de cada grupo.

As crianças das classes populares, nessa conjuntura, enquanto sujeitos de aprendizagem em uma sociedade globalizada, sofrem as consequências da organização social capitalista, na qual sua condição social demarca um lugar de inferioridade, de desprestigio social. As crianças das classes populares são expropriadas do direito à Educação, mesmo estando inseridas em instituições de ensino, pois em tais instituições ainda vivenciamos situações excludentes, de baixa expectativa do docente em relação à aprendizagem dos estudantes, simplificação do conhecimento mediante transposição didática que descaracteriza o objeto de ensino e limitação da principal atividade mobilizadora da criança, o brincar. 
É preciso compreender o significado da expressão "classes populares" e para tanto, partimos das proposições realizada por Wanderley (2010, p. 41):

\begin{abstract}
Uma maioria de oprimidos, marginalizados, discriminados, e, mais proximamente excluídos. A configuração é ampla, e inclui os membros contidos nos dois ângulos antes indicados: os privados dos bens materiais necessários a uma vida digna; aqueles cujas opressões são dadas pela discriminação racial, étnica e sexual; os migrantes estrangeiros; os marginalizados (desempregados, subempregados, trabalhadores da economia submersa, os miseráveis englobando mendigos, menores abandonados, prostitutas etc.); os explorados (operários e lavradores); a franja inferior do setor de serviços (pequenos funcionários, professores primários, pequenos comerciantes etc.).
\end{abstract}

Os sujeitos populares, conforme definição do autor, corresponde também ao que Freire (1987) conceitua como "oprimidos", como sujeitos empobrecidos pelo sistema capitalista, categoria histórica composta por uma multiplicidade de identidades, porém com pontos comuns que os englobam dentro de grupo marcado pelas mazelas em curso que atinge todos os cantos do mundo.

O entendimento sobre a expressão "classes populares" é ampliada por Streck (2008, p. 13), e abrange múltiplas formas de dominação:

A cultura popular deixou de ser lida num viés estritamente classista e abriu-se para abrigar a pluralidade de manifestações e de formas de expressão que perfazem as realidades vividas e sentidas. A ideia de classes populares, hoje, combina formas de dominação do passado, com efeitos opressivos das lógicas capitalistas contemporâneas.

Conceituar "classes populares" configura-se como um árduo esforço, dada à complexidade do termo, porque ele é multifacetado, atravessado por modulações, síntese da história da humanidade, assumindo em diferentes contextos variados significados, tais como "Educação Popular" e "cultura popular", expressões que se intercruzam e estão vinculados uns aos outros desde sua gênese. Sacristán (1999, p. 175) apresenta com clareza e objetividade a origem do conceito cultura popular e a sua importância enquanto conteúdo legítimo no currículo escolar:

Esse conceito de cultura popular foi criado pelos cultos e conservadores românticos alemães. O gosto e a importância dada àquilo que é local é uma das características intelectuais da pós-modernidade. Se entendemos tudo por cultura e existem culturas delimitadas, coerentes consigo mesmas, e não podemos hierarquizá-las, a popular deve encontrar um lugar ao lado e no nível de qualquer outra, evitando o etnocentrismo que suporia escolher somente dentro das culturas próprias de algumas determinas classes sociais. (...) A recuperação dessa cultura popular pode ser apresentada na Educação como um ato de justa restituição e recuperação de uma parte mutilada do acervo cultural, até como um compromisso da escola com as classes populares e como uma oportunidade de vivificar os conteúdos escolares.

(C) ETD- Educação Temática Digital $\quad$ Campinas, SP $\quad$ v.23 $\quad$ n.4 $\quad$ p. 982-1001 out./dez. 2021 
A escola pública é um espaço profícuo para relacionarmos com os componentes da cultura popular como a pluralidade e a relação horizontal entre os saberes. Enquanto conteúdo legítimo no currículo escolar, a cultura popular pode ser recuperada e apresentada na educação, uma vez que a instituição pública recebe majoritariamente sujeitos das classes populares. Depreendemos que as imagens, concepções, pensamentos e ideias, que se amalgamam no engendramento das representações sobre as crianças e dos(as) alunos(as), implicam na forma como hoje reconhecemos e nos comportamos com os(as) alunos(as), como os(as) percebemos na instituição escolar, seus modos de aprender e de se relacionar com a comunidade escolar. Destarte, nos propomos conhecer e compreender as representações docentes sobre os(as) alunos(as) das classes populares.

\section{O CAMPO TEÓRICO E OS CAMINHOS PERCORRIDOS}

No estudo realizado, optamos pela abordagem qualitativa, pois nos possibilita imergir nas esferas da subjetividade e do simbolismo, fundamentados no contexto social, com peculiaridades de crença, valores, representações e significados específicos a cada indivíduo ou grupo (BOGDAN; BIKLEN, 1994, p. 49).

Dessa forma, tomamos como objeto de estudo as representações sociais de docentes sobre alunos(as) das classes populares matriculados(as) em instituições públicas de Educação Infantil e a repercussão dessas em seus processos de escolarização.

Para tanto, adotamos o conceito de Representação Social, criado por Moscovici em 1961, como fundamento teórico-metodológico, porquanto, segundo o autor, "[...] as representações significam a circulação de todos os sistemas de classificações, todas as imagens e todas as descrições, mesmo as científicas" (MOSCOVICI, 2007, p. 37).

As pesquisas em Educação, conforme ressalta Alves-Mazzotti (2008, p. 20-21), em parceria com os estudos em representações sociais, têm significativo impacto sobre a prática educativa, uma vez que:

O estudo das representações sociais parece ser um caminho promissor para atingir esses propósitos na medida em que investiga justamente como se formam e como funcionam os sistemas de referência que utilizamos para classificar pessoas e grupos e para interpretar os acontecimentos da realidade cotidiana. Por suas relações com a linguagem, a ideologia e o imaginário social e, principalmente, por seu papel na orientação de condutas e das práticas sociais, as representações sociais constituem elementos essenciais à análise dos mecanismos que interferem na eficácia do processo educativo. 
O(a) aluno (a) e o(a) infante são construtos humanos carregados de representações e, bem como as representações presentes em nosso universo simbólico, as que o(a) professor(a) possui sobre os(as) estudantes também são construídas socialmente, ao longo do tempo. Alves-Mazzotti (2010, p. 2) argumenta que as representações "[...] apresentam em sua estrutura elementos arcaicos, ligados à memória do grupo, ao lado de outros, mais vinculados às comunicações e interações cotidianas".

Os estudos dedicados às Representações de Professores(as) sobre crianças matriculadas na primeira etapa da Educação Básica, Educação Infantil, ainda são escassos, como apontam estudos de Alves-Mazzotti $(2008,2010)$, e a literatura fica ainda mais exígua quando tratamos de pesquisas sobre representações de alunos (as) das classes populares.

Nesse contexto, reconhecemos a pertinência da pesquisa realizada, uma vez que procuramos entender de que modo as representações influem no ensino-aprendizagem, durante a primeira etapa do processo escolar formal, com vistas a compor elementos para repensarmos as práticas pedagógicas instituídas nas escolas públicas urbanas, no município de Uberlândia, nas quais os estudantes são majoritariamente das classes populares, conforme documentos dos arquivos da Secretaria Municipal de Educação (SME) ${ }^{3}$.

A escolha de docentes que trabalham especificamente na pré-escola ${ }^{4}$ (primeiro e segundo períodos) levou em consideração a abrangência de atendimento, pois é na préescola que se encontra a maior quantidade de alunos matriculados na Educação Infantil em todo o País é a etapa a ser universalizada até o final de 2016 em todo Brasil, conforme prevê o Plano Nacional de Educação (PNE) 2014-20245.

A partir do referencial teórico metodológico das representações sociais, adotamos procedimentos para a construção de dados para compor informações referentes ao perfil

\footnotetext{
${ }^{3}$ Segundo levantamento recente realizado pela Assessoria Pedagógica da Educação Infantil da Secretaria Municipal de Educação de Uberlândia, 77,69\% das famílias, que possuem crianças matriculadas na referida modalidade de ensino e que responderam à Pesquisa sobre Renda Familiar 2014, possuem renda mensal de um a três salários mínimos e pertencem, por conseguinte, a um grupo socioeconômico de baixo poder aquisitivo, o que configura, segundo Wanderley (2010), uma das características das classes populares.

${ }^{4}$ A Educação Infantil, primeira etapa da Educação Básica, atende crianças de 0 a 5 anos em creches e pré-escolas. $O$ atendimento na creche é realizado para crianças de 0 a 3 anos de idade. Já na pré-escola são atendidas crianças de 4 a 5 cinco anos, distribuídas no primeiro e segundo período, respectivamente.

${ }^{5}$ O Plano Nacional de Educação (PNE), decênio 2014 - 2024, publicado pelo Ministério da Educação, define compromissos assumidos para melhoria da Educação em todo Brasil. Consolida 20 metas para garantia do acesso, permanência e conclusão dos estudos das crianças jovens e adultos. A primeira meta refere-se à Educação Infantil: "Meta 1: universalizar, até 2016, a Educação Infantil na pré-escola para as crianças de 4 (quatro) a 5 (cinco) anos de idade e ampliar a oferta de Educação Infantil em creches, de forma a atender, no mínimo, 50\% (cinquenta por cento) das crianças de até 3 (três) anos até o final da vigência deste PNE" (BRASIL, 2014, p. 9).

(C) ETD-Educação Temática Digital Campinas, SP $\quad$ v.23 $\quad$ n.4 $\quad$ p.982-1001 out./dez. 2021
}


docente e à prática educativa dos(as) profissionais que atuam na modalidade de ensino eleita para realização deste estudo, com vistas a contextualizar o universo social a que esses sujeitos pertencem. Decidimos, desse modo, por trabalhar com dois instrumentos: questionário (Censitário e Associação Livre de Palavras - ALP) e Entrevista Semiestruturada.

O questionário foi organizado em duas partes: a primeira refere-se aos dados censitários (levantamento de informações pessoais, de formação e profissionais) e a segunda composta de sete expressões indutoras de associação livre, relativas às representações docentes sobre alunos das classes populares. As sete expressões indutoras utilizadas foram: 1) Criança é ...; 2) Infância é ...; 3) Aluno é ...; 4) Aluna é ...; 5) Alunos(as) das classes populares; 6) Ensinar alunos(as) das classes populares e 7) Aprendizagem de alunos(as) das classes populares.

O outro instrumento adotado foi a entrevista semiestruturada, realizada após a aplicação do questionário censitário e da ALP, envolvendo três temas: a) História de vida; b) Formação acadêmica e c) Representações sobre Educação Infantil e alunos(as) das classes populares. Os temas foram eleitos tendo como base o referencial teórico adotado para análise das categorias que compõem o objeto em investigação.

O questionário foi respondido por 58 professoras e, desse total, 9 aceitaram conceder a entrevista. As palavras evocadas durante a realização da ALP formam um sistema consistente de categorias que são configurados em um quadro com quatro quadrantes. Cada quadrante confere graus diferentes de centralidade para as palavras que o compõem (SÁ, 2002). Os quadrantes, conforme Justo e Camargo (2014, p. 30), indicam:

\footnotetext{
O primeiro quadrante (superior esquerdo) indica as palavras que têm alta frequência (uma frequência maior que a média) e baixa ordem de evocação (aquelas que foram mais prontamente evocadas). Essas seriam as prováveis indicadoras do núcleo central de uma representação. No segundo quadrante (superior direito), temos a primeira periferia, com as palavras que têm alta frequência, mas que tiveram ordem média maior, ou seja, não foram tão prontamente evocadas. No terceiro quadrante (inferior esquerdo), a zona de contraste contém elementos que foram prontamente evocados, porém com frequência abaixo da média. Por fim, a segunda periferia no quarto quadrante (inferior direito) indica os elementos com menor frequência e maior ordem de evocação.
}

Os quadrantes referem-se a uma análise de tipo prototípica; uma técnica simples e eficaz obtida por meio da submissão das planilhas e/ou matrizes a programas específicos que cruzam os critérios de frequência e ordem de evocação provenientes dos testes de evocações livre. 
Segundo a TRS, os elementos dispostos nos quatro quadrantes são móveis, apresentam dinamicidade, da mesma maneira que nossa realidade dialética. Dessa forma, a Representação Social pode ser alterada; quanto mais próximos os elementos (evocações) diferentes estiverem daquelas que compõem o núcleo central, maior a possibilidade de mudança da representação construída sobre determinado objeto. Objetivamos, por conseguinte, por meio da análise dos quadrantes, indicar as representações sociais, mas também verificar as possibilidades de transformação dessas sobre o objeto em investigação.

As informações censitárias foram digitadas em planilhas do Microsoft Excel $2016^{\circledR} \mathrm{e}$ devidamente tratadas ${ }^{6}$. Esse procedimento permitiu gerar dados estáticos sobre o perfil docente. Já os dados oriundos da ALP foram submetidos no Programa Interface de $R$ pour les Analyses Multidimensionnelles de Textes et de Questionnaires, denominado Iramuteq ${ }^{7}$.

Assumimos também o compromisso de proceder a aplicação da técnica de análise de conteúdo elaborada por Bardin (2009) para analisar as declarações obtidas por meio da ALP e nas entrevistas. As entrevistas foram gravadas e transcritas, conforme autorização dos sujeitos, posteriormente, foram codificadas e organizadas. Essa categorização seguiu os procedimentos elencados na análise de conteúdo: pré-análise, exploração do material e tratamento dos resultados - a inferência e a interpretação.

O caminho percorrido para acessar e tratar os dados nos possibilitou identificar e apreender as representações docentes sobre os(as) alunos(as) das classes populares e por meio da triangulação do material coletado, detectamos a estrutura representacional, os sentidos e significados atribuídos ao objeto em investigação pelos sujeitos participantes. Evidenciamos que a triangulação nos permite cruzar diferentes dados e pontos de vista sobre um mesmo objeto e, de forma contextualizada, apontar a convergência seja de natureza quantitativa ou qualitativa (CRESWELL, 2007, p. 32-33).

\section{QUE AS REPRESENTAÇÕES REVELAM: DIALOGANDO COM OS DADOS}

A pesquisa foi realizada em cinco unidades de Educação Infantil, com 58 (cinquenta e oito) professoras ${ }^{8}$ da Rede Pública Municipal que trabalhavam com crianças matriculadas na pré-escola, entre quatro e cinco anos de idade. Os sujeitos participantes foram escolhidos em conformidade com os seguintes critérios: uma unidade escolar de cada polo setorial e que

\footnotetext{
${ }^{6}$ Os dados foram digitados em planilhas do Microsoft Excel $2016{ }^{\circledR}$, normalizados segundo campo semântico das palavras e corrigidos ortograficamente.

${ }^{7}$ O download do Iramuteq pode realizado acessando o domínio: www.iramuteq.org

8 Nesse universo de profissionais participantes, apenas duas professoras são contratadas, as demais são profissionais efetivas que ingressaram no serviço público por meio de concurso, que representam $96,56 \%$ das participantes da pesquisa.
}

(C) ETD- Educação Temática Digital $\quad$ Campinas, SP $\quad$ v.23 $\quad$ n.4 $\quad$ p.982-1001 out./dez. 2021 
abrigassem o maior quantitativo de crianças definidas das classes populares (essa seleção ancorou-se em dados oficiais já citados na nota de rodapé no. 4).

O convite para participar da investigação foi realizado pessoalmente em visitas in loco. Alcançamos a participação de 15,6\% do total de docentes da Rede Municipal de Uberlândia. As 58 (cinquenta e oito) professoras responderam ao questionário - censitário e ALP - e 9 concordaram em, além de responder aos questionários, conceder também entrevista.

O grupo investigado é constituído por mulheres que se autodeclararam, em maioria, brancas (58\%) e católicas (43\%). As participantes se formaram em instituições de Ensino Superior da rede pública e privada, sendo a UFU responsável pela formação de $34,48 \%$ das professoras. Ainda sobre o aspecto formativo, as professoras relatam que participam da formação contínua promovida pela Secretaria Municipal de Educação de Uberlândia.

No que se refere a formação inicial, as docentes declararam que o curso de licenciatura não foi suficiente para prepará-las para o exercício da docência; já a formação contínua tem oferecido elementos que contribuem para a ação educativa desenvolvida pelas participantes.

A análise indicou que o grupo investigado possui representações similares sobre os(as) alunos(as) das classes populares. Na sequência, no Quadro 1, pontuamos as expressões indutoras e as principais palavras evocadas pelas professoras, no 10 quadrante:

Quadro 1 - Palavras evocadas para cada expressão indutora

\begin{tabular}{|c|c|}
\hline Expressão indutora & Palavras mais evocadas no 1o quadrante \\
\hline Criança é .... & Alegria; Amor; Inteligente; Esperta \\
\hline Infância é... & Brincar; Diversão; Aprendizagem; Descoberta. \\
\hline Aluno é ... & Aprendizagem; Agitado; Esperto; Inteligente. \\
\hline Aluna é... & Meiga; Delicada; Carinhosa; Esperta. \\
\hline
\end{tabular}

Fonte: Dados obtidos por meio da ALP. Programa Iramuteq, Uberlândia, 2016.

No Quadro 1 estão organizadas as palavras com maior Ordem Média de Frequência (OMF), situadas no primeiro quadrante, denominado por Abric (1994) como núcleo central. As palavras relacionadas são as que possuem maior conexão e coesão na composição da representação. Para Campos, Silva e Cicillini (2015, p. 447):

(C) ETD- Educação Temática Digital $\quad$ Campinas, SP $\quad$ v.23 $\quad$ n.4 $\quad$ p.982-1001 out./dez. 2021


A complexidade da investigação das representações sociais requer um cuidado criterioso, principalmente por sustentarem as práticas sociais diante do objeto representado. Definidas as temáticas diante de determinado assunto, podemos chegar ao núcleo de sentidos e significância. Nesse sentido, deve-se ficar claro que o importante não são as "palavras" em si ou o rastreamento de significados por meio de outros indícios, mas sim a síntese que esses indícios permitem elaborar a respeito das representações sociais.

Atentas aos critérios para verificar a estrutura representacional, a partir da compreensão que está além do sentido restrito das palavras, mas sim na síntese entre esses indícios e o contexto em que os fenômenos se desenvolvem, procuramos analisar os quadrantes. Nesse viés, reconhecemos nas representações docentes, sobre criança e infância, a marca do pensamento moderno, em que a fase infantil é concebida como uma etapa da vida humana que deve ser lúdica, prazerosa e de aprendizado. Tal representação vincula-se a ideia da criança como sujeito universal e abstrato - a criança burguesa membro de uma família nuclear patriarcal sem marcas socioculturais, conforme descrito por Ariès (1981).

Apesar do constructo histórico e das diversas produções no campo de estudos e pesquisas sobre a infância, constatamos nas representações docentes, concepções coesas, arraigadas e concordantes com o modelo eurocêntrico, ideal e romantizado de criança e infância e indicam pouca possibilidade de alteração.

Sobre as expressões indutoras "Aluno é..." e "Aluna é...", também observamos a ligação com ideal moderno, patriarcal que cristalizou o pensamento normativo de quem é o sujeito que aprende. Sob essa lógica, o homem ocupa uma posição superior à mulher, de tal forma que as funções sociais femininas são secundarizadas, ou melhor dizendo, subalternizadas. A valorização social não decorre apenas do gênero, mas são oriundas das diversas marcas sócio históricas, também usadas para manutenção da sociedade capitalista, excludente e desigual (SACRISTÁN, 2005).

Constatamos, porém, com suporte nas representações docentes, reduzidos indícios de mudanças das representações das alunas, no que se refere ao campo cognitivo, porque nas periferias mais próximas ao núcleo central há evocações ligadas ao campo cognitivo, conforme Quadro 2: 
Quadro 2 - Palavras evocadas para cada expressão indutora

\begin{tabular}{|c|c|c|}
\hline Expressão indutora & $\begin{array}{c}\text { Palavras mais evocadas } \\
\text { no 1o quadrante }\end{array}$ & $\begin{array}{c}\text { Palavras mais evocadas } \\
\text { no 2o quadrante }\end{array}$ \\
\hline Aluno é ... & $\begin{array}{c}\text { Aprendizagem; Agitado; } \\
\text { Esperto; Inteligente. }\end{array}$ & Falante; Criativo, Curioso, Carinhoso. \\
\hline Aluna é... & $\begin{array}{c}\text { Meiga; Delicada; Carinhosa; } \\
\text { Esperta. }\end{array}$ & $\begin{array}{c}\text { Inteligente; Aprendizagem; Vaidosa, } \\
\text { Amorosa; Tranquila; Criativa. }\end{array}$ \\
\hline
\end{tabular}

Fonte: Dados obtidos por meio da ALP. Programa Iramuteq, Uberlândia, 2016.

As evocações "esperta", localizada no primeiro quadrante, e "inteligente", "aprendizagem" e "criativa", situadas no $2^{\circ}$ quadrante, as quais já haviam sido pronunciadas para se tratar do aluno do gênero masculino - apontado pelas participantes como um sujeito com alto potencial de aprendizagem, apareceram com maior incidência na periferia mais próxima ao núcleo central, indicando assim uma movimentação que poderá transformar a representação sobre "aluna".

Cogitamos que esta possível alteração se relaciona com o aumento da veiculação em diversos espaços midiáticos dos discursos e ações dos movimentos feministas, os quais lutam pelos direitos das mulheres e de outras minorias, como das crianças e dos(as) negros(as).

Desde a Educação Infantil, as crianças das classes populares são submetidas a um modelo de escolarização de baixa qualidade em função da desvalorização social do grupo a que pertencem (PATTO, 1993). A hierarquização das representações docentes sobre a exclusão, a discriminação e a baixa expectativa em relação ao aprendizado, é mais contundente quando tratamos dos(as) alunos(as) das classes populares, conceito compreendido nesta investigação como a classe trabalhadora, classe operária, ou então como denomina Freire (1996) "os esfarrapados do mundo".

Nesse sentido, afirmamos que ser criança e aluno(a) das classes populares é ser membro de um coletivo crivado por condições as quais seus grupos sociais pertencem, a esse respeito coadunamos com Sacristán (2005, p. 22):

A infância é objetivamente heterogênea porque existem infâncias socialmente diferentes e desiguais. (...) A infância das classes populares está longe de ser a mesma que a das classes abastadas: quanto a sua duração, forma de vivê-la, experiências tidas durante a mesma. 
O modo de viver e de experimentar a infância em espaços educativos se deu de modo diferente para cada grupo social. Oliveira (2002) salienta que desde o Brasil Colônia o cuidado com a educação refletia o sentimento da sociedade em função da classe social a que as crianças pertenciam, existia um tratamento dualizado, a "paparicação" e a moralização. As crianças de famílias abastadas, eram consideradas frágeis, inocentes, ingênuas, exigiam cuidados e deveriam ser preservadas das mazelas sociais e por esses motivos recebiam a educação domiciliar por preceptores; já aquelas oriundas de famílias pobres eram alvo de uma educação religiosa, moralizante, assistencialista e se ancorava no discurso que visava a diminuição de futuros problemas sociais.

Observamos que, mediante a análise das entrevistas, as representações sociais das professoras a respeito dos(as) alunos(as) das classes populares ainda estão relacionadas com o ideário colonizador, no qual a baixa condição financeira familiar impacta na expectativa de aprendizagem e desenvolvimento deles(as). As principais palavras evocadas por elas, "carente" e "família", revelam que as representações se vinculam à ausência de estrutura familiar, conforme ilustrado pela fala de uma participante da pesquisa:

\begin{abstract}
[...] eu não queria identificar assim, mas a gente identifica pela carência mesmo, as vezes pelo modo de vestir, pelo jeito, pelo que a criança traz para gente, pelo que ela fala. Crianças que precisam de mais carinho. (...) algumas delas tem dificuldade porque não tem o estimulo em casa, as vezes você manda uma tarefa e não volta o caderno, então não tem estímulo para aquela pessoa para estar ali, não insistem e nem questionam: "Não filho, vamos fazer!", “O que você fez hoje?” Nem ao menos para perguntar o que a criança fez naquele dia. As nossas crianças em geral são das classes populares, mas essas crianças que nos mostra um pouco mais de carência, de estímulo, a gente pensa que essas estão mais ligadas a classe popular que se deve a condição familiar, tudo se deve a base familiar (Professora 01/2016)
\end{abstract}

As condições materiais e simbólicas das famílias de acordo com as professoras, constituem um contexto desfavorável para o desenvolvimento escolar dessas crianças. Observamos também que a mesma situação se repete para a representação docentes sobre o ensino e a aprendizagem das classes populares, pois constatamos um paradoxo, expresso, por exemplo, nas palavras "prazeroso" e "difícil", retratando o quanto as ações educativas são complexas. De fato, como apontam Sacristán (2005) e Imbernón (1999), ensinar é uma ação difícil e tem se tornado cada vez mais complexa em função da globalização e capitalismo tardio.

A esse respeito, Arroyo (2004) nos lembra que os(as) alunos(as) são outros, são sujeitos sócio históricos e que, muitas vezes, os(as) professores(as), desconsideram o tempo e o espaço dos sujeitos aprendentes. Essa incompatibilidade entre tempo e sujeitos vem causando descompasso que repercute sobre a qualidade dos processos educacionais. $O$ descompasso é ainda mais expressivo quando se trata da escola pública brasileira, que atende

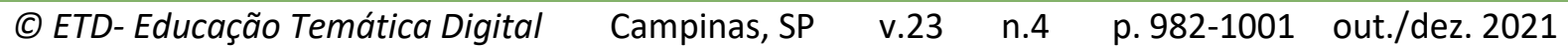


$70 \%$ da população mais pobre do nosso pais e que ao longo dos anos sofre com a adoção de políticas públicas influenciada pelos organismos internacionais, cuja proposta baseia-se exclusivamente na formação para o mercado de trabalho a partir de currículos baseados em necessidades mínimas, controlado mediante a aplicação de avaliações em larga escala, cuja proposta não corrobora para formação ampla - emancipadora e crítica (LIBÂNEO; FREITAS 2018).

Além disso, devemos considerar a escassez de recursos, situação que foi ampliada a partir de 2016 com a aprovação da Emenda Constitucional no 95 que prevê, por 20 anos, o congelamento de gastos em Educação e Saúde. A esse respeito Campos, Silva e Cicillini (2015, p. 453 - 454) asseveram que:

\begin{abstract}
No Brasil, uma parcela significativa de estudantes matriculados nas escolas públicas encontra-se em situação de fracasso escolar, algo que ocorre num contexto de vigência de legislação educacional nacional e de acordos internacionais que preconizam o direito à escolarização, independentemente de classe social, gênero, raça/etnia, deficiência, dentre outras condições do sujeito. Tal processo de exclusão se apresenta, muitas vezes, camuflado por discursos institucionalizados, os quais contribuem para asseverar as relações de desprestígio.
\end{abstract}

A exclusão institucionalizada nas escolas torna-se ainda mais evidente quando identificamos e analisamos a representação das professoras sobre o ensino e aprendizagem das classes populares. A recorrente culpabilização da família pelo fracasso escolar dos(as) alunos(as), como relata Patto (1993), advém da limitada expectativa da sociedade em relação aos mais pobres, ocasionando uma desvalorização social dessas crianças.

A aprendizagem escolar está atravessada por diversos fatores, porém a situação socioeconômica não pode ser um elemento limitador. Streck (2009) e Novais (2002) ressaltam as pedagogias fundamentadas no campo das teorias e práticas em Educação Popular como possibilidade de ressignificação da Educação pública e, portanto, das ações educativas que promovam o desenvolvimento holístico dos sujeitos aprendentes. Nessa acepção, consideramos oportuna a proposta freiriana de formação permanente, pois têm-se o(a) professor(a) sujeito da sua formação que parte do diálogo, porque "não é no silêncio que os homens se fazem, mas na palavra, no trabalho, na ação-reflexão" (FREIRE, 1987, p. 44). Nessa direção, a formação assume a configuração de grupos, comunidades que se dedicam a tomar como necessidade formativa o lócus principal, ou seja, da escola são retirados os temas de interesse, temas que são trabalhados pelos(as) docentes com base em uma matriz críticoemancipatória. 
Reiteramos que essa organização formativa foi desenvolvida na gestão freiriana a frente da Secretaria Municipal de São Paulo, entre 1989 e 1992 e, a proposta apostava na escola como espaço privilegiado para formação permanente do professorado:

(...) a escola como um espaço coletivo de ensino-aprendizagem, na qual a formação se dirigia a todo o grupo de educadores, em oposição às formações em que os professores participam individualmente. Esperava-se que o educador pudesse experienciar, no grupo, o mesmo processo que era esperado que desenvolvesse junto aos educandos, nas escolas. Ou seja, uma prática de análise e de crítica da realidade, no transcurso de uma vivência da metodologia dialógica que permitisse a construção de conhecimentos com a compreensão de que o educador e o educando são sujeitos cognitivos, afetivos, sociais e históricos (SAUL E SAUL, 2016, p. 26).

Nas escolas municipais em Uberlândia, durante a gestão 2013 a 2016 - período em que a pesquisa apresentada neste texto foi realizada -, por meio das Rodas de Conversas ${ }^{9}$ realizaram-se diálogos com os(as) professores(as), onde foram levantadas as necessidades formativas nas próprias unidades de ensino. A começar dessas ações, o coletivo de docentes desenvolveu, com o apoio do Centro Municipal de Estudos e Projetos Educacionais Julieta Diniz (Cemepe), planos de formação que buscaram caminhar para garantia de uma educação com qualidade socialmente referenciada (RIBEIRO, 2017, p. 92).

Diante desse pensamento, é necessário e urgente que os cursos de formação inicial e contínua contemplem em suas propostas fundamentos da perspectiva freiriana, cujos princípios são encontrados também na educação popular, já que Freire foi o percussor no Brasil desta área de conhecimento. Segundo Freire (1996), a prática educativa e a formação docente devem insistir na busca pelo "ser mais", atentando às condições materiais em que vivem os(as) educandos(as).

Nas proposições de Zeichner (2003, p. 11), as responsabilidades atribuídas à docência nos instigam a pensar sobre a possibilidade de novas diretrizes de formação de professores que contribuam para:

[...] a diminuição das desigualdades existentes entre as crianças das classes baixa, média e alta nos sistemas de escola pública de todo o mundo e das injustiças que existem nas sociedades, fora dos sistemas de ensino: em relação ao acesso à moradia, alimentação, saúde, transporte, ao trabalho digno que pague um salário justo e assim por diante. A incerteza que caracteriza o contexto atual está relacionada ao futuro duvidoso que o planeta tem pela frente se as injustiças persistirem e nós continuarmos a ver grandes distâncias na educação e na renda entre ricos e pobres em toda a sociedade.

\footnotetext{
${ }^{9}$ Rodas de conversas são muito utilizadas como espaços instigadores do diálogo e impulsiona a problematização e reflexões sobre diversos temas. Envolve a socialização e troca de saberes voltados para a ação coletiva com vistas a transformação de alguma demanda apontada pelo grupo.
}

(C) ETD- Educação Temática Digital $\quad$ Campinas, SP $\quad$ v.23 $\quad$ n.4 $\quad$ p.982-1001 out./dez. 2021 
Mediante o estudo realizado, depreendemos que, para alcançarmos a excelência nas ações educativas para e com as classes populares, é necessário investir em políticas públicas que fortaleçam a escola pública, tanto no que se refere às condições objetivas para a realização do trabalho docente, quanto na questão da formação permanente. Diante disso, é fundamental entender os sistemas de referência utilizados para orientar e justificar as condutas humanas, tal como proposto neste estudo, por meio das representações sociais, mas para além disso, asseveramos a importância de, por meio desses conhecimentos podemos ressignificar pensamentos e ações a favor de processos educativos que garantam justiça social.

\section{CONSIDERAÇÕES FINAIS}

Reconhecemos que é preciso renovar a nós mesmos para nos tornarmos educadores(as) ousados(as) que não se prendam às amarras cotidianas da reprodução, que acreditem na incompletude humana e na capacidade criativa de sempre poder nos reinventar para (trans)formar nossas realidades.

Como poetizado por Bertold Brech (1986) em O Elogio do aprendizado, é preciso aprender o mais simples, tornarmo-nos rebeldes, no sentido mais radical da palavra, para que professores(as) e alunos(as) "assumam comando", para humanizarem-se. A tomada do "comando" no cenário educativo se faz por meio de ações ancoradas no pensamento crítico que visa desenvolver uma Educação que se funde na vida e com a vida, condição que só tem sentido quando nos permite continuar sonhando, porquanto a utopia é essencial à humanidade, como nos ensina Freire (1996).

Este estudo representa nossa esperança de contribuir com Educação pública, com os sujeitos populares e com os(as) professores(as) brasileiros(as). Frisamos que as reflexões e indagações anunciadas ao longo deste artigo não se esgotam, porque estamos convictas da relevância de pesquisas que incluam a observação das práticas e o desenvolvimento de ações conjuntas entre pesquisadores(as) e docentes. As possibilidades de transformação detectadas relacionam-se com a ruptura da visão idealizada de quem é o(a) aluno(a), mediante a reflexão crítica das representações que subsidiam tal pensamento, investimento na formação para diversidade, autonomia e justiça social por meio dos fundamentos da Educação Popular, cuja proposta dialoga com tais objetivos. É preciso desenvolver mais pesquisas com os (as) docentes de modo cooperativo e participativo, que articulem a observação e análise das práticas pedagógicas com os dados expressos pelas vozes dos(as) participantes.

(C) ETD- Educação Temática Digital $\quad$ Campinas, SP $\quad$ v.23 $\quad$ n.4 $\quad$ p.982-1001 out./dez. 2021




\section{REFERÊNCIAS}

ALVES-MAZZOTTI, Alda Judith. Representações sociais: aspectos teóricos e aplicações à Educação. Revista Múltiplas Leituras, São Paulo, v.1, n. 1, p. 18-43, jan. / jun. 2008.

ALVES-MAZZOTTI, Alda Judith. As representações dos professores sobre o aluno. In: OLIVEIRA, D. A.; DUARTE, A. M. C.; VIEIRA, L. M. F. Dicionário: trabalho, profissão e condição docente. Belo Horizonte, MG: UFMG/Faculdade de Educação, 2010. CDROM.

ANDRADE, Daniela Barros da Silva Freire; SANTOS, Marisa Faria. O outro do adulto e do professor: representações sociais sobre criança, segundo licenciados de pedagogia da UFMT. Nuances: estudos sobre Educação, Presidente Prudente, SP, ano XV, v. 16, n. 17, p. 105-117, jan./dez. 2009.

ARIÈS, Philippe. História social da criança e da família. Traduzido por Dora Flaksman. Rio de Janeiro: LTC, 1981.

ARROYO, Miguel González. Imagens quebradas: trajetórias e tempos de alunos e mestres. Petrópolis, RJ: Vozes, 2004.

BRANDÃO, Carlos Rodrigues. O que é educação popular. 2.ed. São Paulo: Brasiliense, 1983.

BRANDÃO, Carlos Rodrigues; ASSUMPÇÃO, Raiane. Cultura rebelde: escritos sobre a educação popular ontem e agora. v. 2. Série Educação Popular. 2009.

BRECH, Bertolt. Elogio do aprendizado. In: . Poemas 1913-1956, São Paulo: Brasileiro, 1986.

CAMPOS, Vanessa Bueno; SILVA, Fernanda Duarte Araújo; CICILLINI, Graça Aparecida. Os sentidos dos silêncios na educação: representações sociais de professores formadores da Universidade Federal de Uberlândia - MG. ETD - Educação Temática Digital, Campinas, SP, v. 17, n. 2, p. 442- 462, ago. 2015. ISSN 1676-2592. Disponível em:

http://periodicos.sbu.unicamp.br/ojs/index.php/etd/article/view/8635725 . Acesso em: 28 ago. 2015.

CUNHA, Myrtes Dias da; SANTOS, Tatiani Rabelo Lapa. Crianças, infâncias e educação: um encontro entre sociologia da infância e educação popular. Ensino Em Re-Vista, Uberlândia, v.21, n.2, p.353-362, jul. / dez. 2014. 
FREIRE, Paulo. Pedagogia do oprimido. Rio de Janeiro: Paz e Terra, 1987.

FREIRE, Paulo. Pedagogia da autonomia. Saberes necessários à prática educativa. São Paulo: Paz e Terra, 1996.

KUHLMANN JÚNIOR, Moysés. Infância e educação infantil: uma abordagem histórica. 7. ed. Porto Alegre: Mediação, 2015.

LIBÂNEO, José Carlos; FREITAS, Raquel Aparecida Marra da Madeira. Políticas educacionais neoliberais e escola pública: uma qualidade restrita de educação escolar. Goiânia: Editora Espaço Acadêmico, 2018.

MOSCOVICl, Serge. Representações sociais: investigações em psicologia social. Tradução de Pedrinho A. Guareschi. 5. ed., Petrópolis: Vozes, 2007.

NOVAIS, Gercina Santana. A Educação Popular nas Instituições de Ensino Oficial: uma alternativa possível. Revista de Educação Popular, Uberlândia, n.1, p. 17-22, nov. 2002

OLIVEIRA, Zilma de Moraes Ramos de. Educação Infantil: fundamentos e métodos. São Paulo: Cortez, 2002.

PATTO, Maria Helena Souza. A produção do fracasso escolar: histórias de submissão e rebeldia. São Paulo: T. A. Queiroz,1993.

RIBEIRO, Andréa Porto. Representações sociais de professoras da educação infantil sobre alunos(as) das classes populares. Dissertação (mestrado) - Universidade Federal de Uberlândia, Programa de Pós-Graduação em Educação, 2017.

SACRISTÁN, José Gimeno. Poderes instáveis em Educação. Porto Alegre: ArtMed, 1999.

SACRISTÁN, José Gimeno. $\mathbf{O}$ aluno como invenção. Tradução de Dayse Vaz de Moraes. Porto Alegre: Artmed, 2005.

STRECK. Danilo Romeu. Educação popular e movimentos sociais: tensões e desafios na América Latina. Anais da 32. Reunião anual da ANPED, de 4 a 7 de outubro. Disponível em: http://32reuniao.anped.org.br/arquivos/sessao especial/32\%20ra\%20\%20sessao\%20especial\%20-\%20DANILO\%20ROMEU\%20STRECK.pdf . Acesso em: 13 de dezembro de 2016.

STRECK. Danilo Romeu. A pesquisa em educação popular e a educação básica. Práxis Educativa, Ponta Grossa, v. 8, n. 1, p. 111-132, jan. / jun. 2013. Disponível em: http://www.revistas2.uep.br/index.php/praxiseducativa . Acesso em: 11 de dezembro de 2016.

(C) ETD-Educação Temática Digital $\quad$ Campinas, SP $\quad$ v.23 $\quad$ n.4 $\quad$ p.982-1001 out./dez. 2021


SAUL, Ana Maria; SAUL, Alexandre. Contribuições de Paulo Freire para a formação de educadores. Educar em Revista, Curitiba, Brasil, n. 61, p. 19-35, jul. / set. 2016. Disponível em: http://www.scielo.br/pdf/er/n61/1984-0411-er-61-00019.pdf. Acesso em: 19 de outubro de 2018.

ZEICHNER, Kenneth. M. Formando professores reflexivos para uma educação centrada no aluno: possibilidades e contradições. In: BARBOSA, Raquel Lazzari Leite. Formação de educadores: desafios e perspectivas. São Paulo: Unesp, 2003.

Revisão gramatical realizada por: Carina Diniz Nascimento.

E-mail: carinadnascimento@gmail.com . 